\title{
Patient-Reported Outcome Measures in Adult Patients Diagnosed with Epilepsy Being Treated with Perampanel
}

\author{
Brian D Moseley', Shaloo Gupta ${ }^{2}$, Nate Way $^{2}$, Jonathon Wright ${ }^{2}$, John C Rowland ${ }^{2}$, \\ Victoria E Barghout ${ }^{3}$, Feride Frech ${ }^{4}$, Craig Plauschinat $\mathbb{D}^{4}$ \\ 'Department of Neurology and Rehabilitation Medicine, University of Cincinnati, Cincinnati, OH, 45267, USA; ${ }^{2}$ Real World Evidence, Cerner Enviza, \\ Malvern, PA, 19355, USA; ${ }^{3}$ VEB HealthCare LLC, Morristown, NJ, 07960, USA; ${ }^{4}$ Health Economics, Outcomes Research, and Real World Evidence, \\ Eisai Inc., Nutley, NJ, 07II0, USA \\ Correspondence: Craig Plauschinat, Eisai Inc, 200 Metro Blvd, Nutley, NJ, 07II0, USA, Tel + I 55I-284-92I6, Fax +I 20I-692-I804, \\ Email craig_plauschinat@eisai.com
}

\begin{abstract}
Background: Epilepsy is a complex disorder that can affect patients' medical, psychological, and social well-being. The purpose of this study was to evaluate the patient-reported outcome (PRO) measures of health-related quality of life (HRQoL), satisfaction, and adherence in adult patients diagnosed with epilepsy treated with perampanel in the United States (US).

Methods: A US-based, multicenter, observational cross-sectional survey was completed by 61 patients taking perampanel with or without other antiseizure medications (ASMs). Respondents were $\geq 18$ years old, had a physician-confirmed diagnosis of epilepsy, used perampanel for $\geq 4$ months, and provided informed consent. Patients responded to questions concerning their demographic characteristics, treatment history, experiences before perampanel, experiences while taking perampanel, HRQoL, treatment satisfaction, and medication adherence.

Results: Patients $(\mathrm{N}=61)$ were 42.8 years old on average; majority were female $(63.9 \%)$ and white $(75.4 \%)$. Mean time on perampanel was 2.5 years, with sodium channel blockers often (55.7\%) used concomitantly with perampanel. Patients reported, on average, 5.5 (standard deviation $[\mathrm{SD}]=13.2$ ) seizures/month after initiating perampanel, whereas these same patients reported experiencing 20.4 $(\mathrm{SD}=60.0)$ seizures/month prior to perampanel. When comparing their experience on perampanel with their experience with previous ASMs, more patients "strongly agreed" that perampanel allowed them to live a more normal life (36.1\% vs $27.5 \%)$ and worked as intended if they missed taking a dose (16.4\% vs 7.8\%). Average satisfaction scores were high, with ratings of 71.8 for effectiveness, 84.0 for convenience, and 71.9 for global satisfaction (0-100 scores). Perampanel use was associated with improvements in HRQoL and fewer symptoms of depression and anxiety. The majority of patients were adherent (62.3\%) to perampanel.
\end{abstract}

Discussion: Perampanel use was associated with reductions in number of seizures, better HRQoL, and high adherence rates. These results provide initial evidence that perampanel can be an effective, tolerable, and valid option for patients with epilepsy in the real world.

Keywords: epilepsy, perampanel, quality of life, medication adherence, healthcare resource use

\section{Introduction}

Epilepsy is one of the most prevalent neurological diseases, affecting an estimated 3 million individuals in the United States (US) and 50 million people worldwide. ${ }^{1}$ The International League Against Epilepsy defines epilepsy as 2 or more seizures occurring greater than 24 hours apart, or a single seizure with additional features that are associated with an enduring predisposition of the brain to future seizures. ${ }^{2}$ Epilepsy is an extremely heterogeneous disease because of its different causes, different seizure types, its ability to vary in severity, its impact from person to person, and its range of co-existing conditions.

Many patients remain unsatisfied with their antiseizure treatment. Indeed, whereas half of patients with epilepsy are completely seizure free after their first antiseizure medication (ASM) is administered, a precipitous drop in efficacy has been documented in the setting of a second ASM. ${ }^{3}$ Approximately one-third of epileptic patients remain refractory to 
drug treatment, continue to experience uncontrolled seizures, and experience adverse events (AEs) that can contribute to poor health-related quality of life (HRQoL). ${ }^{4}$ The substantial number of pharmacoresistant patients underscores the urgent need for the development of new strategies that can enhance epilepsy management, ${ }^{5,6}$ including new agents that have longer half-lives, treat multiple seizure types, and can provide improved effectiveness, as well as once-daily dosing that can promote greater adherence. ${ }^{7,8}$

Over the last two decades, the market for ASMs has expanded, with over 20 different drugs currently available to patients. ${ }^{9}$ The current study focused on one of the recent market entrants, perampanel, and assessed its use in the realworld setting from the patient perspective. Perampanel is a first-in-class ASM that has been shown to significantly improve seizure control in epileptic patients. ${ }^{10}$ This agent is an orally active, highly selective, non-competitive antagonist of the alpha-amino-3-hydroxy-5-methyl-4-isoxazolepropionic acid glutamate receptor; ${ }^{11}$ it effectively blocks the uncontrolled synchronous spread of electrical signals in the brain (ie seizures). ${ }^{4,10}$ Perampanel has a relatively long half-life (70-100 hours), thus enabling once-daily dosing and ensuring the concentration of the drug rises and falls gradually, thereby eliminating many potential AEs or withdrawal symptoms ${ }^{6,10,12-16}$ and helping to promote adherence, patient satisfaction, and HRQoL. ${ }^{13,15,16}$

Since US Food \& Drug Administration approval, clinical and real-world studies continue to suggest that perampanel is an efficacious, effective, and tolerable treatment for some forms of epilepsy, either as adjunctive therapy or as monotherapy. ${ }^{4,17,18}$ Post-market studies on the effectiveness of perampanel outside the experimental setting are limited and, in general, consist of retrospective claims database studies. This real-world study expanded on the existing literature by assessing the patient experience with perampanel in a post-market, real-world setting in the US, from the patients' perspective, to describe patient demographics and characteristics, HRQoL, treatment satisfaction, and medication adherence.

\section{Materials and Methods Study Design and Period}

A multicenter, cross-sectional study of patients with a confirmed diagnosis of epilepsy and confirmation of current perampanel usage was conducted from November 2018 to October 2019.

\section{Study Setting and Participants}

A total of 61 US patients from 6 neurology sites completed up to a 30-minute online survey. Physicians invited patients to participate who met the following inclusion criteria:

1. Age 18 years or older

2. Physician-confirmed diagnosis of epilepsy

3. Currently on perampanel for a minimum of 4 months as confirmed by a physician

4. Provide informed consent

5. Ability to read and write in English

Recruitment efforts were made to maximize representativeness of the sample in order to reflect real-world practice. However, due to potential variations in treatment patterns and size of the population of interest, recruitment was done through convenience sampling only. The physicians assisting with this research screened their patients for study eligibility and identified those eligible to participate. Once a patient was found eligible for inclusion, the investigator informed the patient about the study. For patients who expressed interest in participating, the investigator discussed the patient consent form and addressed any of the potential subject's questions. If paper consent was required by the site, the patient was asked to read and sign the informed consent. Otherwise, patients were instructed to use the survey link and asked to sign the patient consent online.

Eligible patients were provided with a unique de-identified survey link to access either by a device (computer, tablet) of their own or one provided by the site at the time of their visit. The link directed patients to the welcome page, in which there was the statement of informed consent for this study. In order to proceed with the survey, all patients were required 
to consent electronically, regardless of whether a paper copy had been previously signed. No personal information was collected, and the only patient-identifying information remained at the site in the study binder.

\section{Instruments and Data Collection}

The survey was developed using a multi-step process. First, a targeted review of the literature was undertaken to identify which validated scales had been utilized in the past in patients with epilepsy. Survey design experts conducted a pilot phase of the study, which included 45-minute in-depth telephone interviews of patients who have been diagnosed with epilepsy ( $\mathrm{N}=3)$. The pilot phase ensured question clarity, identified missing concepts and topics important to patients, and assessed the respondents' ability to understand the content and instructions. The survey instrument was then developed and reviewed by an epileptologist who suggested further revisions before the survey was finalized.

The survey collected sociodemographic (age, sex, race/ethnicity, health insurance, and education) and clinical characteristics (body mass index [BMI], smoking frequency, select comorbidities, age at epilepsy diagnosis, type of epilepsy seizures, current ASM prescriptions, and duration and dosage of perampanel usage).

Patient experience immediately before and during perampanel use was recorded, including average number of seizures per month, average length of a seizure, and action(s) taken as a result of having a seizure.

Patient ratings of ASM regimen attributes (immediately before perampanel use and during perampanel use) were assessed on a five-point Likert scale, where 1="strongly agree", 2="agree", 3="neither agree nor disagree", 4="disagree", and 5="strongly disagree". Patients were asked about the following ASM attributes: "I worried that I would have another seizure if I missed a dose of my epilepsy medication"; "My epilepsy medication(s) eliminated my fear of sudden unexpected death in epilepsy (SUDEP)"; "My epilepsy medication(s) worked as intended if I missed taking a dose"; "My epilepsy medication(s) allowed me to live a normal life"; "My epilepsy medication(s) were affordable"; "My epilepsy medication(s) made me feel independent"; "My epilepsy medication(s) had a convenient pill size"; "My epilepsy medication(s) had a convenient dosing schedule"; "My epilepsy medication(s) made me confident that I would not have another seizure if I missed taking a dose"; and "My epilepsy medication(s) were not well-tolerated".

Patient ratings of HRQoL immediately before and during perampanel use were assessed on a five-point Likert scale, where 1="strongly disagree", 2="somewhat disagree", 3="neither agree nor disagree", 4="somewhat agree", and $5=$ "strongly agree". A patient's well-being was evaluated with the following statements: "My epilepsy makes it difficult for me to perform daily functions such as work, social activities, or driving around"; "My quality of life is good"; "I have a lot of energy"; "I feel depressed"; and "I feel anxious".

Data on satisfaction with perampanel treatment were captured using the abbreviated Treatment Satisfaction Questionnaire for Medication - 9 item (TSQM-9) instrument, measuring outcomes over the prior 2 to 3 weeks, or since the patient last used the medication. The TSQM-9 provides a unique opportunity to measure satisfaction with medication in such naturalistic studies where measuring patient-reported side effects may interfere with the study objectives. ${ }^{19}$ The TSQM-9 is a psychometrically robust and validated instrument comprising three domains: effectiveness (questions 1-3), convenience (questions 4-6), and global satisfaction (questions 7-9). Likert scales were used for all questions. Seven-point scales, ranging as follows, were used for the corresponding questions: (a) 1="extremely dissatisfied" to 7= "extremely satisfied" (questions 1-3 and 9); (b) 1="extremely difficult" to 7="extremely easy" (questions 4-5); and (c) 1="extremely inconvenient" to 7="extremely convenient" (question 6). Five-point scales, ranging as follows, were used for the corresponding questions: (a) $1=$ "not at all confident" to $5=$ "extremely confident" (question 7); and (b) 1="not at all certain" to 5="extremely certain" (question 8). The TSQM-9 domain scores were calculated as recommended by the instrument's authors and described in detail elsewhere. ${ }^{20}$ TSQM-9 domain scores range from 0 to 100 , with higher scores representing higher satisfaction in that domain.

Satisfaction with perampanel was further evaluated by asking patients their satisfaction, relative to their satisfaction with the ASM regimen that immediately preceded perampanel with the following response options: "Much more satisfied with current medication"; "Somewhat more satisfied with current medication"; "Neither more satisfied nor more dissatisfied with current medication"; "Somewhat more dissatisfied with current medication"; and "Much more dissatisfied with current medication". Satisfaction with the size of the perampanel tablet was assessed on five-point Likert scale, where 1="Extremely satisfied", 2="Very satisfied", 3="Satisfied", 4="Somewhat satisfied", and 5="Not at all satisfied". 
Medication adherence was collected using the Morisky, Green, Levine Scale (MGLS), a structured self-report measure of medication-taking behavior that was first validated in antihypertensive drugs in outpatient settings. ${ }^{21}$ It is a four-item questionnaire with dichotomous response categories with yes or no. The rationale behind the four items was the drug errors of omission, which could occur in any or all of several ways: "forgetting", "carelessness", "stopping the drug when feeling better", or "stopping the drug when feeling worse". A score of 4 was categorized as adherent, and scores 0-3 were non-adherent.

\section{Sample Size}

A sample size of 150 was targeted based on the estimated number of adult patients taking perampanel, as initially provided by the investigators at the six sites.

\section{Data Analysis}

All data management and analyses were performed using SAS Software, Version 9.4 (Copyright C 2013, SAS Institute Inc., Cary, NC, USA). The overall sample was characterized on the variables listed in the Instruments and Data Collection section, using descriptive statistics, including frequencies and percentages for categorical variables, and means and standard deviations for continuous variables. Pearson correlations were conducted to assess the relationship between HRQoL and treatment satisfaction. Due to the small sample size reached versus that targeted, multivariable regressions adjusting for covariates were not employed.

\section{Results}

A total of 61 patients completed the survey, provided informed consent, and met the inclusion/exclusion criteria of the study (83 patients accessed the survey, response rate=73.5\%). Demographics and patient characteristics are presented in Table 1. Patients $(\mathrm{N}=61)$ were, on average, 42.8 years old (standard deviation $[\mathrm{SD}]=12.9)$; the majority were female $(63.9 \%)$, white (75.4\%), and had health insurance (96.7\%). The majority had a high-school degree (or equivalent) or higher level of education (96.7\%). The proportion of patients receiving disability benefits was 39.3\%. The average BMI of patients was 29.5 $(\mathrm{SD}=7.6)$. The majority of patients had never smoked (67.2\%). The most frequently stress-related comorbidities experienced within the past 12 months included: depression (59.0\%), anxiety (49.2\%), and headache/migraine (37.7\%).

Patients reported using levetiracetam (31.1\%), lacosamide (26.2\%), and lamotrigine (23.0\%) concomitantly with perampanel. Overall, sodium-channel blockers were the most common type of ASMs used concomitantly with perampanel (55.7\%), with the average number of current ASM medications reported to be $3.0(\mathrm{SD}=1.2)$.

Patients currently taking a perampanel regimen reported, on average, $5.5(\mathrm{SD}=13.2)$ seizures per month, whereas these same patients reported experiencing $20.4(\mathrm{SD}=60.0)$ seizures per month prior to perampanel use. The sample size for the pre-perampanel group is smaller, as 10 patients reported not taking any epilepsy prescription medication prior to starting treatment on perampanel. Patients currently taking perampanel also reported slightly shorter seizure durations, relative to those reported pre-perampanel $(44.3 \%$ vs $37.3 \%$ reported seizures $<1$ minute long) (Table 2$)$.

When comparing their experience on perampanel with their experience with previous ASMs, more patients "strongly agreed" that perampanel: allowed them to live a more normal life (36.1\% vs $27.5 \%)$, worked as intended if they missed taking a dose ( $16.4 \%$ vs $7.8 \%$ ), had a more convenient dosing schedule (55.7\% vs $51.0 \%)$, and engendered more feelings of independence (31.1\% vs $27.5 \%$ ) (Table 3$)$.

\section{HRQoL}

Perampanel use was also associated with improvements in HRQoL. When comparing their experience with perampanel with their experience with previous ASMs, more patients taking perampanel "strongly agreed" that they now have more energy (13.1\% vs $9.8 \%)$, are less depressed (6.6\% vs $11.8 \%)$, and are less anxious $(6.6 \%$ vs $11.8 \%)$ than before taking perampanel (Table 4). 
Table I Demographics, Clinical, and Treatment Characteristics

\begin{tabular}{|c|c|}
\hline & Total $(\mathbf{N}=61)$ \\
\hline Age, mean $\pm S D$ & $42.8 \pm 12.9$ \\
\hline Female, n (\%) & $39(63.9)$ \\
\hline \multicolumn{2}{|l|}{ Ethnicity/race, n (\%) } \\
\hline African American/Black & $6(9.8)$ \\
\hline Native American or Alaskan native & I (I.6) \\
\hline Hispanic & 7 (I I.5) \\
\hline White & $46(75.4)$ \\
\hline Prefer not to answer & I (I.6) \\
\hline Currently have health insurance, $n(\%)$ & $59(96.7)$ \\
\hline \multicolumn{2}{|l|}{ Education, n (\%) } \\
\hline No high school diploma & $2(3.3)$ \\
\hline High school graduate or equivalent & $32(52.5)$ \\
\hline Associate's or bachelor's degree & $21(34.4)$ \\
\hline Graduate degree & $6(9.8)$ \\
\hline BMI, mean \pm SD & $29.5 \pm 7.6$ \\
\hline \multicolumn{2}{|l|}{ Smoking frequency, n (\%) } \\
\hline Never & $4 I(67.2)$ \\
\hline Past smoker & $13(2 \mid .3)$ \\
\hline Current smoker & 7 (II.5) \\
\hline Age at epilepsy diagnosis, mean \pm SD & $18.7 \pm 13.2$ \\
\hline \multicolumn{2}{|l|}{ Type(s) of seizure, n (\%) } \\
\hline Partial/focal seizures & $38(62.3)$ \\
\hline Primary generalized seizures & $28(45.9)$ \\
\hline Do not know/not sure (\%) & $8(13.1)$ \\
\hline \multicolumn{2}{|c|}{ Top 5 comorbidities experienced within the past 12 months, $\mathrm{n}(\%)$} \\
\hline Depression & $36(59.0)$ \\
\hline Anxiety & $30(49.2)$ \\
\hline Headache/migraine & $23(37.7)$ \\
\hline Insomnia & $13(21.3)$ \\
\hline Diarrhea & $12(19.7)$ \\
\hline Duration of perampanel use [years], mean \pm SD & $2.5 \pm 2.7$ \\
\hline \multicolumn{2}{|l|}{ Current perampanel dose, $\mathrm{n}(\%)$} \\
\hline$\leq 4 \mathrm{mg}$ & $19(31.1)$ \\
\hline
\end{tabular}

(Continued) 
Table I (Continued).

\begin{tabular}{|c|c|}
\hline & Total $(\mathbf{N}=6 \mathrm{I})$ \\
\hline $6-8 \mathrm{mg}$ & $29(47.6)$ \\
\hline $10-12 \mathrm{mg}$ & $12(19.7)$ \\
\hline Do not know/not sure & I ( $(1.6)$ \\
\hline \multicolumn{2}{|l|}{ Current concomitant ASM combinations with perampanel, n (\%) } \\
\hline Sodium channel blocker ${ }^{\mathrm{a}}$ & $34(55.7)$ \\
\hline Synaptic vesicle protein $2 \mathrm{~A}$ binding ${ }^{\mathrm{b}}$ & $24(39.3)$ \\
\hline Gamma-aminobutyric acid analog ${ }^{c}$ & $12(19.7)$ \\
\hline Multiple mechanisms $^{\mathrm{d}}$ & $22(36.1)$ \\
\hline Total number of current ASM prescriptions with perampanel, mean \pm SD & $3.0 \pm 1.2$ \\
\hline
\end{tabular}

Notes: aPhenytoin, lamotrigine, carbamazepine, oxcarbazepine, lacosamide. ${ }^{\mathrm{b}}$ Brivaracetam, levetiracetam. ${ }^{\mathrm{c}}$ Tiagabine, clonazepam, pregabalin, gabapentin, primidone, phenobarbital, vigabatrin. ${ }^{d}$ Valproic acid, felbamate, topiramate, zonisamide.

Abbreviations: ASM, antiseizure medication; BMI, body mass index; SD, standard deviation.

Table 2 Seizures (Pre- versus Post-Perampanel Experience)

\begin{tabular}{|c|c|c|}
\hline & Pre-Perampanel $(\mathrm{N}=5 \mathrm{I})$ & Post-Perampanel $(\mathrm{N}=6 \mathrm{I})$ \\
\hline Average number of seizures per month, mean \pm SD & $20.4 \pm 60.0$ & $5.5 \pm 13.2$ \\
\hline \multicolumn{3}{|l|}{ Average length of a seizure, $n(\%)$} \\
\hline Less than I minute & $19(37.3)$ & $27(44.3)$ \\
\hline I-2 minutes & $21(4 I .2)$ & $23(37.7)$ \\
\hline $3-4$ minutes & $4(7.8)$ & $4(6.6)$ \\
\hline More than 4 minutes & $7(13.7)$ & $7(11.5)$ \\
\hline \multicolumn{3}{|l|}{ Action(s) taken when experienced a seizure, $\mathrm{n}(\%)$} \\
\hline Made an appointment with my doctor & $13(25.5)$ & $15(24.6)$ \\
\hline Called my doctor's office to speak with nurse/on-call doctor & $17(33.3)$ & $17(27.9)$ \\
\hline Visited the emergency Room & $17(33.3)$ & II (18.0) \\
\hline Took prescription ASM & $17(33.3)$ & $17(27.9)$ \\
\hline Nothing & $9(17.6)$ & $13(2 \mid .3)$ \\
\hline
\end{tabular}

Abbreviations: ASM, antiseizure medication; SD, standard deviation.

\section{Treatment Satisfaction}

Patients were satisfied with perampanel and its attributes. Results from the TSQM-9 indicated that patients reported an average score of $71.8(\mathrm{SD}=19.7)$ for effectiveness, $84.0(\mathrm{SD}=14.0)$ for convenience, and $71.9(\mathrm{SD}=22.9)$ for global satisfaction (Table 5). Nearly one-third of patients (31.1\%) reported being "much more satisfied with current medication", followed by "neither more satisfied nor more dissatisfied with current medication" (26.2\%), and "somewhat more satisfied with current medication" (19.7\%). The vast majority of patients were satisfied with the size of their perampanel 
Table 3 Patient Ratings of ASM Regimen Attributes (Pre- versus Post-Perampanel Experience)

\begin{tabular}{|c|c|c|}
\hline & Pre-Perampanel $(\mathbf{N}=5 \mathrm{I})$ & Post-Perampanel $(\mathrm{N}=6 \mathrm{I})$ \\
\hline \multicolumn{3}{|c|}{ I worry that I will have another seizure if I miss a dose of my epilepsy medication, $\mathrm{n}(\%)$} \\
\hline Strongly agree & $19(37.3)$ & $25(41.0)$ \\
\hline Somewhat agree & $19(37.3)$ & $16(26.2)$ \\
\hline Neither agree nor disagree & $7(13.7)$ & $8(13.1)$ \\
\hline Somewhat disagree & $2(3.9)$ & $7(11.5)$ \\
\hline Strongly disagree & $4(7.8)$ & $5(8.2)$ \\
\hline \multicolumn{3}{|c|}{ My epilepsy medication(s) eliminate(s) my fear of SUDEP, $n$ (\%) } \\
\hline Strongly agree & $13(25.5)$ & $14(23.0)$ \\
\hline Somewhat agree & $8(15.7)$ & $17(27.9)$ \\
\hline Neither agree nor disagree & $21(4 I .2)$ & $18(29.5)$ \\
\hline Somewhat disagree & $3(5.9)$ & $7(11.5)$ \\
\hline Strongly disagree & $6(11.8)$ & $5(8.2)$ \\
\hline \multicolumn{3}{|c|}{ My epilepsy medication(s) work(s) as intended if I missed taking a dose, $\mathrm{n}(\%)$} \\
\hline Strongly agree & $4(7.8)$ & $10(16.4)$ \\
\hline Somewhat agree & $9(17.6)$ & $12(19.7)$ \\
\hline Neither agree nor disagree & $22(43.1)$ & $22(36.1)$ \\
\hline Somewhat disagree & $8(15.7)$ & $9(14.8)$ \\
\hline Strongly disagree & $8(15.7)$ & $8(13.1)$ \\
\hline \multicolumn{3}{|c|}{ My epilepsy medication(s) allow(s) me to live a normal life, n (\%) } \\
\hline Strongly agree & $14(27.5)$ & $22(36.1)$ \\
\hline Somewhat agree & $16(31.4)$ & $19(31.1)$ \\
\hline Neither agree nor disagree & $8(15.7)$ & $9(14.8)$ \\
\hline Somewhat disagree & $10(19.6)$ & $5(8.2)$ \\
\hline Strongly disagree & $3(5.9)$ & $6(9.8)$ \\
\hline \multicolumn{3}{|c|}{ My epilepsy medication(s) are affordable, $\mathrm{n}(\%)$} \\
\hline Strongly agree & $18(35.3)$ & $21(34.4)$ \\
\hline Somewhat agree & $15(29.4)$ & $14(23.0)$ \\
\hline Neither agree nor disagree & $7(13.7)$ & $13(21.3)$ \\
\hline Somewhat disagree & $7(13.7)$ & $6(9.8)$ \\
\hline Strongly disagree & $4(7.8)$ & $7(11.5)$ \\
\hline \multicolumn{3}{|c|}{ My epilepsy medication(s) make me feel independent, $\mathrm{n}(\%)$} \\
\hline Strongly agree & $14(27.5)$ & $19(31.1)$ \\
\hline Somewhat agree & $12(23.5)$ & $21(34.4)$ \\
\hline
\end{tabular}

(Continued) 
Table 3 (Continued).

\begin{tabular}{|l|c|c|}
\hline & Pre-Perampanel (N=5 I) & Post-Perampanel (N=6 I) \\
\hline Neither agree nor disagree & $13(25.5)$ & $9(14.8)$ \\
\hline Somewhat disagree & II (2I.6) & $7(11.5)$ \\
\hline Strongly disagree & $1(2.0)$ & $5(8.2)$ \\
\hline
\end{tabular}

My epilepsy medication(s) have a convenient pill size, $\mathrm{n}(\%)$

\begin{tabular}{|l|c|c|}
\hline Strongly agree & $24(47.1)$ & $32(52.5)$ \\
\hline Somewhat agree & $14(27.5)$ & $21(34.4)$ \\
\hline Neither agree nor disagree & $4(7.8)$ & $4(6.6)$ \\
\hline Somewhat disagree & $9(17.6)$ & $2(3.3)$ \\
\hline Strongly disagree & $0(0.0)$ & $1(1.6)$ \\
\hline My epilepsy medication(s) have a convenient dosing schedule, n (\%) & $34(55.7)$ \\
\hline Strongly agree & $26(51.0)$ & $21(34.4)$ \\
\hline Somewhat agree & $19(37.3)$ & $3(4.9)$ \\
\hline Neither agree nor disagree & $3(5.9)$ & $3(4.9)$ \\
\hline Somewhat disagree & $1(2.0)$ & $0(0.0)$ \\
\hline Strongly disagree & $2(3.9)$ & \multicolumn{2}{|c|}{} \\
\hline
\end{tabular}

My epilepsy medication(s) make me confident that I would not have another seizure if I missed taking a dose, $\mathrm{n}(\%)$

\begin{tabular}{|l|c|c|}
\hline Strongly agree & $4(7.8)$ & $13(21.3)$ \\
\hline Somewhat agree & $15(29.4)$ & $13(21.3)$ \\
\hline Neither agree nor disagree & $10(19.6)$ & $11(18.0)$ \\
\hline Somewhat disagree & $9(17.6)$ & $13(21.3)$ \\
\hline Strongly disagree & $13(25.5)$ & $11(18.0)$ \\
\hline
\end{tabular}

My epilepsy medication(s) were not well tolerated, $\mathrm{n}(\%)$

\begin{tabular}{|l|c|c|}
\hline Strongly agree & $3(5.9)$ & N/A \\
\hline Somewhat agree & $14(27.5)$ & N/A \\
\hline Neither agree nor disagree & $13(25.5)$ & N/A \\
\hline Somewhat disagree & $6(11.8)$ & N/A \\
\hline Strongly disagree & $15(29.4)$ & N/A \\
\hline
\end{tabular}

Abbreviations: ASM, antiseizure medication; N/A, not applicable; SUDEP, sudden unexpected death in epilepsy.

tablet (98.3\%) (Table 5). Overall, satisfaction with perampanel was positively correlated with satisfaction with the size of the perampanel tablet (Pearson correlation coefficient $\mathrm{r}=0.3$ ).

\section{Medication Adherence}

Based on the MGLS, the average reported medication adherence score was 3.46 ( $\mathrm{SD}=0.85$; range, $0-4)$. The majority of patients $(\mathrm{N}=38,62.3 \%)$ were completely adherent to their current medication regimen that included perampanel. 
Table 4 Patient Ratings of Health-Related Quality of Life (Pre- versus Post-Perampanel Experience)

\begin{tabular}{|c|c|c|}
\hline & Pre-Perampanel $(\mathrm{N}=5 \mathrm{I})$ & Post-Perampanel $(\mathrm{N}=6 \mathrm{l})$ \\
\hline \multicolumn{3}{|c|}{ My epilepsy makes it difficult for me to perform daily functions, $n$ (\%) } \\
\hline Strongly agree & II (2I.6) & II (I8.0) \\
\hline Somewhat agree & $10(19.6)$ & $19(31.1)$ \\
\hline Neither agree nor disagree & $7(13.7)$ & II (18.0) \\
\hline Somewhat disagree & $10(19.6)$ & $7(11.5)$ \\
\hline Strongly disagree & $13(25.5)$ & $13(21.3)$ \\
\hline \multicolumn{3}{|l|}{ My quality of life is good, $n$ (\%) } \\
\hline Strongly agree & $13(25.5)$ & $18(29.5)$ \\
\hline Somewhat agree & $22(43.1)$ & $23(37.7)$ \\
\hline Neither agree nor disagree & $9(17.6)$ & $8(13.1)$ \\
\hline Somewhat disagree & $5(9.8)$ & $9(14.8)$ \\
\hline Strongly disagree & $2(3.9)$ & $3(4.9)$ \\
\hline \multicolumn{3}{|l|}{ I have a lot of energy, $\mathrm{n}(\%)$} \\
\hline Strongly agree & $5(9.8)$ & $8(13.1)$ \\
\hline Somewhat agree & $8(15.7)$ & $12(19.7)$ \\
\hline Neither agree nor disagree & $16(31.4)$ & $19(31.1)$ \\
\hline Somewhat disagree & $14(27.5)$ & $14(23.0)$ \\
\hline Strongly disagree & $8(15.7)$ & $8(13.1)$ \\
\hline \multicolumn{3}{|l|}{ I feel depressed, n (\%) } \\
\hline Strongly agree & $6(11.8)$ & $4(6.6)$ \\
\hline Somewhat agree & $10(19.6)$ & $20(32.8)$ \\
\hline Neither agree nor disagree & $8(15.7)$ & $14(23.0)$ \\
\hline Somewhat disagree & $12(23.5)$ & $12(19.7)$ \\
\hline Strongly disagree & $15(29.4)$ & II (18.0) \\
\hline \multicolumn{3}{|l|}{ I feel anxious, n (\%) } \\
\hline Strongly agree & $6(11.8)$ & $4(6.6)$ \\
\hline Somewhat agree & $15(29.4)$ & $21(34.4)$ \\
\hline Neither agree nor disagree & II (2I.6) & $19(31.1)$ \\
\hline Somewhat disagree & $7(13.7)$ & $6(9.8)$ \\
\hline Strongly disagree & $12(23.5)$ & II (I8.0) \\
\hline
\end{tabular}

\section{Discussion}

Perampanel appears to be an effective and tolerable treatment for epilepsy with important implications for patients' general well-being. Results from this study provide the first real-world data on perampanel use from the patient's perspective. The impact of epilepsy on patients' daily lives is compounded by side effects commonly associated with 
Table 5 Treatment Satisfaction

\begin{tabular}{|c|c|}
\hline & Total $(\mathrm{N}=6 \mathrm{I})$ \\
\hline TSQM-9: Effectiveness, mean \pm SD & $71.8 \pm 19.7$ \\
\hline TSQM-9: Convenience, mean \pm SD & $84.0 \pm 14.0$ \\
\hline TSQM-9: Global Satisfaction, mean \pm SD & $71.9 \pm 22.9$ \\
\hline \multicolumn{2}{|c|}{$\begin{array}{l}\text { Satisfaction with perampanel regimen, relative to satisfaction with ASM regimen that immediately preceded perampan } \\
\mathrm{n}(\%)\end{array}$} \\
\hline Much more satisfied with current medication & $19(31.1)$ \\
\hline Somewhat more satisfied with current medication & $12(19.7)$ \\
\hline Neither more satisfied nor more dissatisfied with current medication & $16(26.2)$ \\
\hline Somewhat more dissatisfied with current medication & $2(3.3)$ \\
\hline Much more dissatisfied with current medication & $2(3.3)$ \\
\hline \multicolumn{2}{|l|}{ Satisfaction with size of perampanel tablet, $\mathrm{n}(\%)$} \\
\hline Extremely satisfied & $26(42.6)$ \\
\hline Very satisfied & $19(31.1)$ \\
\hline Satisfied & $15(24.6)$ \\
\hline Not at all satisfied or somewhat satisfied & $0(0.0)$ \\
\hline
\end{tabular}

Abbreviations: ASM, antiseizure medication; SD, standard deviation; TSQM-9, Treatment Satisfaction Questionnaire for Medication - 9 item.

ASMs, which further impair patients' HRQoL. Clinical trials have shown perampanel to be an effective and tolerable treatment; however, little prior research exists from the perspective of the perampanel-treated patient on their own health, well-being, and/or HRQoL. ${ }^{6,10,12-15}$ The current study helps to address this gap in the literature. The majority of patients in our study reported being adherent to their current perampanel regimen and experiencing improvements in HRQoL, seizures, and symptoms with perampanel use.

Indeed, patients in our study reported improvements in both seizures and symptoms after taking perampanel, with fewer seizures reported per month and shorter seizure lengths, compared with their previous therapy. Furthermore, compared with previous ASMs, patients were relatively satisfied with perampanel and its attributes. The TSQM-9 results are comparable with prior research involving ASMs in epilepsy patients. ${ }^{22,23}$

The reduction in seizure frequency and duration we observed in these data could have marked implications for patients' HRQoL. Indeed, perampanel was associated with notable improvements in HRQoL, including boosts in energy, less depression, less anxiety, an increased ability to live a normal life, and feelings of independence. In addition, previous studies $^{24,25}$ using administrative claims data found perampanel use was associated with fewer healthcare professional visits, emergency room visits, and hospitalizations due to epilepsy as compared with ASM regimens immediately preceding perampanel use.

For patients with epilepsy, adherence to ASMs is crucial in preventing or minimizing seizures and their cumulative impact on everyday life. Non-adherence can result in breakthrough seizures that occur many months or years after a previous episode and can have serious repercussions on an individual's perceived quality of life, including being unable to drive for a set amount of time, inability to work, and loss of independence. ${ }^{26}$ Previous research suggests a substantial degree of non-adherence to other ASMs $\left(59-66 \%{ }^{27,28}\right.$ ), whereas non-adherence was reported by only $37.7 \%$ of patients taking perampanel in this study. This notable difference could be due to the easier dosing regimen associated with perampanel use, as well as enhanced motivation given the increased efficacy reported by patients.

In line with results from randomized clinical trials, our study results suggest that a perampanel regimen is an effective option for adults with partial seizures and primarily generalized tonic-clonic seizures uncontrolled with other 
medications. ${ }^{29-32}$ A recent literature review by Trinka et al found that based on the published evidence, perampanel has the potential to be used a broad-spectrum ASM. ${ }^{33}$ Many of the real-world results observed in the current study are consistent with those reported in these randomized controlled trials, ${ }^{29-32}$ including a noted reduction in seizures and a tolerable side-effect profile.

The results of this real-world study align with clinical trial data and show that perampanel use could be associated with reducing seizures and side effects. The high level of satisfaction among patients, particularly as compared with previous ASMs, is noteworthy and suggests that perampanel could represent an important treatment option for clinicians to consider in the management of epilepsy. Effective resources are needed to help guide discussions between providers and patients regarding the risks and benefits of perampanel, and to further assess the effect this agent has on patient and clinical outcomes.

These data must be interpreted in the context of the particularities of a real-world study that uses patient-reported outcome measures. First, all measures and outcomes assessed were patient-reported data and these results are susceptible to the potential for inaccurate self-report related to recall bias, variable health literacy, errors in memory, or respondent fatigue. Second, these data are cross-sectional in nature and do not allow for causal conclusions to be made. All findings reported should be conceptualized as associations with perampanel use, rather than outcomes resulting from perampanel use. A longitudinal study or a randomized controlled experiment would be needed to verify any causal relationships among variables. Third, the study sample may not be representative of the total perampanel user patient population in the US due to the site-based nature of this study. Sites were primarily selected out of convenience due to practical challenges with accessing the perampanel patient population. Additionally, there may have been a bias in the types of patients that agreed to participate, and the sample size for the study was small, not reaching the target sample size. Perampanel users with extremely severe symptoms may have been too impaired to participate in this study, yielding a perampanel patient sample that may be less impaired than the general US perampanel patient population.

\section{Conclusions}

Perampanel use was associated with reductions in number of seizures, duration of seizures, and seizure-related symptoms. Patients were more satisfied with a perampanel regimen than their previous ASMs and reported improvements in HRQoL. This is the first study to examine patient-reported outcomes in patients treated with perampanel in the real-world setting. Future research with larger samples is needed to better evaluate perampanel outcomes from a patients' perspective and understand the full impact of both the treatment and disease in both newly diagnosed patients with epilepsy and long-term epilepsy patients.

\section{Abbreviations}

AE, adverse events; ASM, antiseizure medication; BMI, body mass index; HRQoL, health-related quality of life; MGLS, Morisky, Green, Levine Scale; PRO, patient-reported outcomes; SD, standard deviation; SUDEP, sudden unexpected death in epilepsy; TSQM-9, Treatment Satisfaction Questionnaire for Medication - 9 item; US, United States.

\section{Data Sharing Statement}

All data is stored in a local archive. In need of access to the data, the corresponding author can be contacted.

\section{Ethics Approval and Informed Consent}

The research was a multi-site survey conducted at 6 community neurology clinics across the United States. Neither the sites nor the Contract Research Organization (CRO) had an internal Institutional Review Board (IRB); thus, the Western Institutional Review Board (WIRB) was utilized as a central IRB and reviewed the study protocol for an exemption determination under 45 CFR $\S 46.101(b)(2)$. The WIRB determined that the research fits the exemption criteria.

The investigators assisting with this research screened their patients for study eligibility and identified those qualified to participate. Once a patient was found eligible for inclusion, the investigator informed the patient about the study. This 
included discussing the consent form, if paper consent was required by the site, and asking the patient to read and sign the informed consent, or instructed patients that upon entering the survey link they would be directed to a welcome screen to capture patient consent to participate electronically.

Qualifying patients were provided with a unique de-identified survey link to be completed electronically either by a device (computer, tablet) of their own or one provided by the site at the time of their visit. The link took patients to the welcome page, on which there was the statement of informed consent for this study. In order to proceed in with the survey, all patients were required to consent electronically, however, no personal information was collected, and the only patient-identifying information remained at the site in the study binder.

The CRO was responsible for programming and hosting the web-based survey and provided a database of survey links along with instructions for the sponsor to disseminate the survey links to the contracted sites. A patient $\log$ form was provided to sites for recording which survey link was provided to individual patients to enable the site to follow-up with the patient if the survey has not yet been completed.

\section{Acknowledgments}

The authors would like to acknowledge Contessa Fincher, $\mathrm{PhD}$ for her contributions to the research design, site recruitment, and project management while employed at Eisai Inc.

The authors would like to acknowledge the contribution of Errol J. Philip for helping with background research and editing various drafts of the manuscript; he is a paid consultant to Cerner Enviza.

\section{Author Contributions}

Made a significant contribution to the work reported, whether that is in the conception, study design, execution, acquisition of data, or analysis and interpretation: BDM SG NW JW JCR VB FF CP. Have drafted or written, or substantially revised or critically reviewed the article: BDM SG NW JW JCR VB FF CP. Agreed on the journal to which the article will be submitted: BDM SG NW JW JCR VB FF CP. Reviewed and agreed on all versions of the article before submission, during revision, the final version accepted for publication, and any significant changes introduced at the proofing stage: BDM SG NW JW JCR VB FF CP. Agreed to take responsibility and be accountable for the contents of the article: BDM SG NW JW JCR VB FF CP.

All authors made substantial contributions to conception and design, acquisition of data, or analysis and interpretation of data; took part in drafting the article or revising it critically for important intellectual content; agreed to submit to the current journal; gave final approval of the version to be published; and agree to be accountable for all aspects of the work.

\section{Funding}

The authors would like to acknowledge the financial support from Eisai Inc. The funders had no role in data collection, analysis, and interpretation of results.

\section{Disclosure}

Victoria E Barghout is an employee of VEB Healthcare Inc. and is a paid consultant to Eisai Inc., in connection with the study. Feride Frech and Craig Plauschinat are employees of Eisai, Inc., which sponsored this study. Shaloo Gupta, Nate Way, Jonathon Wright, and John C Rowland (at the time of the study execution) are employees of Cerner Enviza (Kantar Health) who were paid consultants to Eisai Inc., in connection with conducting this study and the development of this manuscript. Brian D Moseley is an employee of University of Cincinnati and a consultant to Eisai Inc, UCB, Neurocrine, and LivaNova. He has also received research support from LivaNova, Xenon Pharmaceuticals, and GW Pharma. The authors report no other conflicts of interest in this work.

\section{References}

1. Kobau R, Price PH, Giles HW, Pennell PB, Hargis E. Centers for disease control and prevention managing epilepsy well network. Epilepsy Behav. 2010;19(3):216-217. doi:10.1016/j.yebeh.2010.08.016 
2. Fisher RS, Acevedo C, Arzimanoglou A, et al. ILAE official report: a practical clinical definition of epilepsy. Epilepsia. 2014;55(4):475-482. doi:10.1111/epi.12550

3. Schmidt D, Schachter SC. Drug treatment of epilepsy in adults. BMJ. 2014;348:g254. doi:10.1136/bmj.g254

4. Perampanel: a new add-on treatment for epilepsy. Drug Ther Bull. 2013;51(2):18-20. doi:10.1136/dtb.2013.1.0159

5. Chen Z, Brodie MJ, Liew D, Kwan P. Treatment outcomes in patients with newly diagnosed epilepsy treated with established and new antiepileptic drugs: a 30-year longitudinal cohort study. JAMA Neurol. 2018;75(3):279-286. doi:10.1001/jamaneurol.2017.3949

6. Tsai JJ, Wu T, Leung H, et al. Perampanel, an AMPA receptor antagonist: from clinical research to practice in clinical settings. Acta Neurol Scand. 2018;137(4):378-391. doi:10.1111/ane.12879

7. Löscher W, Klitgaard H, Twyman RE, Schmidt D. New avenues for anti-epileptic drug discovery and development. Nat Rev Drug Discov. 2013;12 (10):757-776. doi:10.1038/nrd4126

8. Wilcox KS, Dixon-Salazar T, Sills GJ, et al. Issues related to development of new antiseizure treatments. Epilepsia. 2013;Suppl 54:24-34. doi:10.1111/epi.12296

9. Chong DJ, Lerman AM. Practice update: review of anticonvulsant therapy. Curr Neurol Neurosci Rep. 2016;16(4):39. doi:10.1007/s11910-0160640-y

10. Satlin A, Kramer LD, Laurenza A. Development of perampanel in epilepsy. Acta Neurol Scand Suppl. 2013;127:3-8. doi:10.1111/ane.12098

11. Greenwood J, Valdes J. Perampanel (Perampanel): a review of clinical efficacy and safety in epilepsy. $P$ T Drug Forecast. 2016;41(11):683-688.

12. Krauss GL, Perucca E, Ben-Menachem E, et al. Long-term safety of perampanel and seizure outcomes in refractory partial-onset seizures and secondarily generalized seizures: results from Phase III extension study 307. Epilepsia. 2014;55(7):1058-1068. doi:10.1111/epi.12643

13. Krauss GL, Perucca E, Kwan P, et al. Final safety, tolerability, and seizure outcomes in patients with focal epilepsy treated with adjunctive perampanel for up to 4 years in an open-label extension of phase III randomized trials: study 307. Epilepsia. 2018;59(4):866-876. doi:10.1111/ epi.14044

14. Wu T, Nagaya Y, Hanada T. Pharmacodynamic and pharmacokinetic interactions of perampanel and other antiepileptic drugs in a rat amygdala kindling model. Seizure. 2014;23(9):732-739. doi:10.1016/j.seizure.2014.06.001

15. Epilepsy Foundation. Perampanel; 2017. Available from: https://www.epilepsy.com/medications/perampanel. Accessed January 19, 2022.

16. Frampton JE. Perampanel: a review in drug-resistant epilepsy. Drugs. 2015;75(14):1657-1668. doi:10.1007/s40265-015-0465-Z

17. Anderson P. FDA okays perampanel monotherapy for partial-onset seizures; 2017. Available from: https://www.medscape.com/viewarticle/883519. Accessed January 19, 2022.

18. Gil-Nagel A, Burd S, Toledo M, et al. A retrospective, multicentre study of perampanel given as monotherapy in routine clinical care in people with epilepsy. Seizure. 2018;54:61-66. doi:10.1016/j.seizure.2017.10.015

19. Bharmal M, Payne K, Atkinson MJ, Desrosiers MP, Morisky DE, Gemmen E. Validation of an abbreviated Treatment Satisfaction Questionnaire for Medication (TSQM-9) among patients on antihypertensive medications. Health Qual Life Outcomes. 2009;7(1):1-10. doi:10.1186/1477-75257-36

20. IQVIA.User manual for the treatment satisfaction questionnaire for medication (TSQM): IQVIA; 2018. Available from: https://www.iqvia.com/ landing/treatment-satisfaction-questionnaire-for-medication-tsqm. Accessed Febrary 02, 2022.

21. Morisky DE, Green LW, Levine DM. Concurrent and predictive validity of a self-reported measure of medication adherence. Med Care. 1986;24 (1):67-74. doi:10.1097/00005650-198601000-00007

22. Sajatovic M, Thompson TR, Nanry K, Edwards S, Manjunath R. Prospective, open-label trial measuring satisfaction and convenience of two formulations of lamotrigine in subjects with mood disorders. Patient Prefer Adherence. 2013;7:411-417. doi:10.2147/PPA.S40271

23. Sweileh WM, Ihbesheh MS, Jarar IS, et al. Self-reported medication adherence and treatment satisfaction in patients with epilepsy. Epilepsy Behav. 2011;21(3):301-305. doi:10.1016/j.yebeh.2011.04.011

24. Faught E, Laliberté F, Wang Z, et al. Health care resource utilization before and after perampanel initiation among patients with epilepsy in the United States. Epilepsia. 2017;58(10):1742-1748. doi:10.1111/epi.13857

25. Li X, Frech F, Plauschinat CA, Gore M. Real-world hospitalization risk in patients with epilepsy treated with perampanel. Epilepsy Behav. 2021;114:107270.

26. Becker MH, Maiman LA. Sociobehavioral determinants of compliance with health and medical care recommendations. Med Care. 1975;13 (1):10-24. doi:10.1097/00005650-197501000-00002

27. Ferrari CM, de Sousa RM, Castro LH. Factors associated with treatment non-adherence in patients with epilepsy in Brazil. Seizure. 2013;22 (5):384-389. doi:10.1016/j.seizure.2013.02.006

28. Jones RM, Butler JA, Thomas VA, Peveler RC, Prevett M. Adherence to treatment in patients with epilepsy: associations with seizure control and illness beliefs. Seizure. 2006;15(7):504-508. doi:10.1016/j.seizure.2006.06.003

29. French JA, Krauss GL, Biton V, et al. Adjunctive perampanel for refractory partial-onset seizures: randomized phase III study 304. Neurology. 2012;79(6):589-596. doi:10.1212/WNL.0b013e3182635735

30. French JA, Krauss GL, Steinhoff BJ, et al. Evaluation of adjunctive perampanel in patients with refractory partial-onset seizures: results of randomized global phase III study 305. Epilepsia. 2013;54(1):117-125. doi:10.1111/j.1528-1167.2012.03638.x

31. Krauss GL, Serratosa JM, Villanueva V, et al. Randomized phase III study 306: adjunctive perampanel for refractory partial-onset seizures. Neurology. 2012;78(18):1408-1415. doi:10.1212/WNL.0b013e318254473a

32. Glauser T, Laurenza A, Yang H, Williams B, Ma T, Fain R. Efficacy and tolerability of adjunct perampanel based on number of antiepileptic drugs at baseline and baseline predictors of efficacy: a phase III post-hoc analysis. Epilepsy Res. 2016;119:34-40. doi:10.1016/j.eplepsyres.2015.11.014

33. Trinka E, Lattanzi S, Carpenter K, et al. Exploring the evidence for broad-spectrum effectiveness of perampanel: a systematic review of clinical data in generalised seizures. CNS Drugs. 2021;35(8):821-837. doi:10.1007/s40263-021-00831-y 


\section{Publish your work in this journal}

Patient Related Outcome Measures is an international, peer-reviewed, open access journal focusing on treatment outcomes specifically relevant to patients. All aspects of patient care are addressed within the journal and practitioners from all disciplines are invited to submit their work as well as healthcare researchers and patient support groups. The manuscript management system is completely online and includes a very quick and fair peer-review system. Visit http://www.dovepress.com/testimonials.php to read real quotes from published authors.

Submit your manuscript here: http://www.dovepress.com/patient-related-outcome-measures-journal 